\title{
THE ENDOGENOUS CREATININE CLEARANCE IN NORMAL SUBJECTS
}

\author{
BY \\ M. H. ROSCOE \\ From the Department of Medicine, Manchester University
}

(RECEIVED FOR PUBLICATION APRIL 12, 1954)

In normal subjects the glomerular filtration rate is relatively constant under standard conditions, and there is little or no change when the urine flow varies. It follows from this that the excretion rate of substances, which are filtered at the glomerulus and neither reabsorbed from nor secreted into the tubules, is constant. It is these substances which can be used to measure the filtration rate.

There is considerable evidence that endogenous creatinine behaves in this way, and this is supported by the data presented in this paper, which show that its excretion is very constant in spite of considerable variations in urine flow, only decreasing slightly at low urine volumes.

\section{Methods}

Four normal subjects were investigated, one on two occasions, at intervals of a year. One- to three-hour samples of urine were obtained from each subject on 28 to 48 days. Those from subjects 1 to 3 were morning specimens. Those from subject 4 were afternoon ones in experiment iv, and in experiment vi morning and afternoon ones, but the results considered separately were the same so are given combined. The minute volume of the samples was varied by dehydration or drinking.

Samples of blood were taken occasionally during each experiment.

Creatinine was estimated by the modified Jaffé reaction in urine and serum (Roscoe, 1953).

Instead of calculating the creatinine excretion rate for each sample of urine, the urinary concentrations (U) are compared with the reciprocals of the urine volume $\left(\frac{1}{u}\right)$. Then if the excretion rate is constant at all urine volumes or $u . U=M, U=M_{\frac{u}{u}}^{1}$ and the regression of $U$ on $\frac{1}{a}$ is a straight line passing through zero on both axes. The rate of excretion is given by the slope of the line, $M$, which can be found by the method of least squares.

Alternatively, if the excretion rate is influenced by the urine flow

$$
\begin{aligned}
\mathbf{u} . \mathbf{U} & =\mathbf{M}+\mathbf{N u} . \\
\mathbf{U} & =\mathbf{M}_{\bar{u}}+\mathbf{N}
\end{aligned}
$$

and the regression of $U$ on $\frac{1}{u}$ is a straight line cutting the co-ordinate axis at $\mathbf{N}$.
The significance of $\mathbf{N}$ depends on the deviation of the values about the regression line ( $\sigma$ y.x).

Mean creatinine clearances (f) are calculated from this expression by dividing by the filtered concentration $(F)$, which is taken as the serum concentration.

$$
\mathrm{f}=\underset{\mathrm{F}}{\mathrm{u} \cdot \mathrm{U}}=\frac{\mathrm{M}}{\mathrm{F}} \quad \text { or } \quad=\frac{\mathrm{M}+\mathrm{Nu} \text {. }}{\mathrm{F}}
$$

The scatter of the individual values of $f$ about the mean is then given by

$$
\frac{\sigma \mathbf{M}}{\mathrm{F}}
$$

\section{Results}

Creatinine Excretion Rates.-The results from subject 3, experiment iv, are shown graphically for high urine flows in Fig. 1 and for low flows in Fig. 2, where $U$ is plotted against $\frac{1}{u}$. At low values of $\frac{1}{u}$ (high urine volumes) $U$ is directly proportional to $\frac{1}{\mathrm{u}}$ and the regression line of $U$ on $\frac{1}{\mathrm{u}}$ goes through zero or $\mathrm{U}=\mathbf{M}_{\overline{\mathrm{u}}}^{1}$. In this case $M=1,000$. At higher values of $\frac{1}{a}$ (low urine volumes) the relationship alters and the regression takes the form $\mathrm{U}=\mathrm{M}_{\mathrm{u}}^{\mathrm{l}}+\mathrm{N}$. Here $\mathrm{M}=706$ and $\mathrm{N}=293$.

The values of $\mathbf{M}$ and $\mathbf{N}$ found in each experiment are shown in Table I. In each case at high urine volumes $\mathbf{N}$ is not significant and the excretion rate is independent of urine flow, but at low volumes $\mathrm{N}$ is significant and the rate falls as the flow decreases.

Since the difference between the relationships at high and low flows is not large it is not obvious at what flow the excretion starts to be influenced by urine volume. In the same experiments the excretion of $\mathrm{Na}, \mathrm{Cl}, \mathrm{K}$, and urea has also been studied, and the results, which it is hoped to publish later, show that a marked change in the excretion of each solute occurs when the creatinine concentration in the urine reaches a certain level. These creatinine levels, which vary in different experiments, have been taken as the dividing values and are shown in Table $I$. The division 


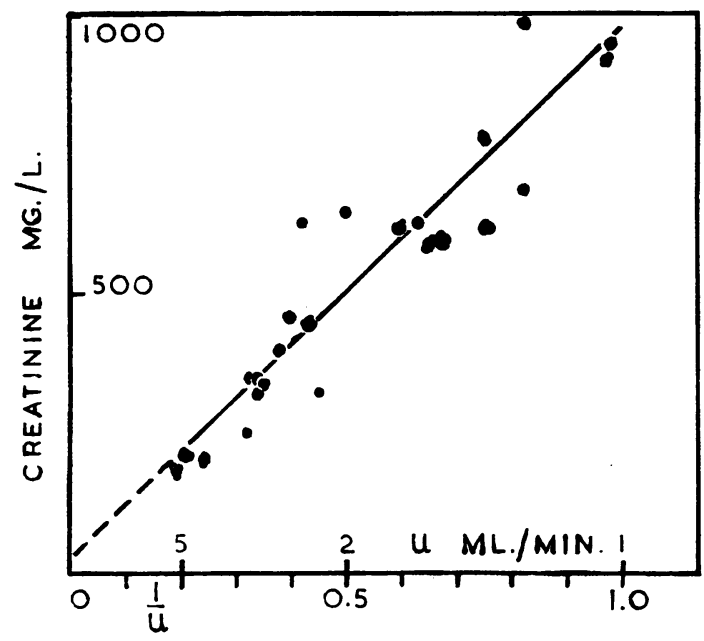

Fig. 1. - The u rinary creatinine concentrations at high urine volume in subject 4 , experiment iv.

could be made at a value of $u$, but since this is a less accurate measurement than $U$, especially when the urine volume is small, this is not advisable. Approximate values of $u$ at which the change occurs are, however, given in Table I. These are means of the values calculated from the dividing values of $\mathrm{U}$, and the regressions at high and low urine flows.

Creatinine Clearance.-Creatinine clearances depend on the plasma creatinine, and when in subject 3 this was estimated several times the mean values of samples obtained during dehydration were higher than those during hydration. This suggests that dehydration influences the creatinine level, either by haemoconcentration or perhaps more probably by reducing the excretion rate. There was no indication that the serum level rose progressively as the urine volume fell, so it

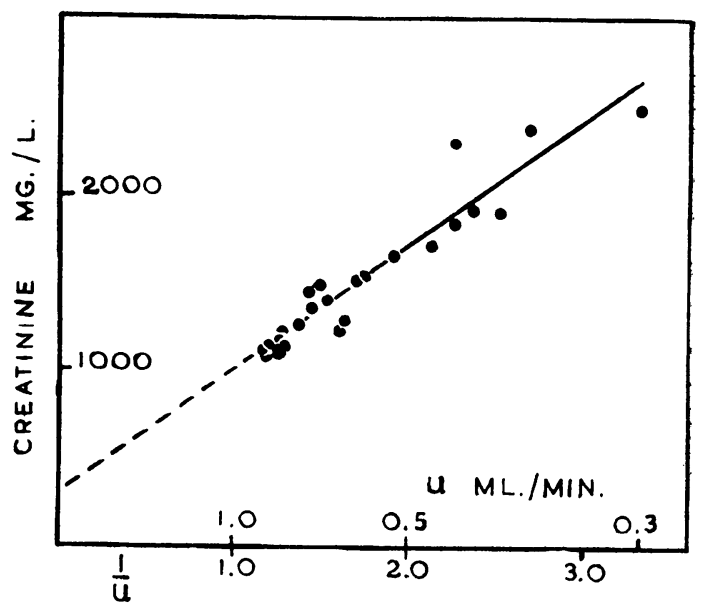

Fig. 2.-The urinary creatinine concentrations at low urine volume in subject 4 , experiment iv.

is only possible to use mean values when these were found, and to consider that when a common value is used the clearances at high flows are perhaps too low and those at low flows too high.

The clearances in each experiment, constant at high urine flows, but falling off as the flow becomes very small, are shown in Table I. The clearances in all experiments, except subject 4 , experiment iv, are higher at the upper limit of the low flow range than at high flows, but this anomaly is probably due to the filtered creatinine value used at low flows being too small, while in subject 4 this was perhaps too large.

In Table II the creatinine clearances at high flows are shown corrected to a surface area of 1.73 sq.m. and compared with the mean inulin clearances given by Smith (1951). The creatinine clearances are $20-27 \%$ lower than the expected inulin clearances.

TABLE I

THE RATE OF CREATININE EXCRETION (u.U) AT DIFFERENT URINE VOLUMES (u), THE FILTERED CREATININE CONCENTRATION (F) AND CREATININE CLEARANCE (f)

\begin{tabular}{|c|c|c|c|c|c|c|c|c|c|c|c|c|c|}
\hline \multirow{2}{*}{$\begin{array}{c}\text { Sub- } \\
\text { ject }\end{array}$} & \multirow{2}{*}{$\begin{array}{c}\text { No. of } \\
\text { Samples } \\
\text { (n) }\end{array}$} & \multirow{2}{*}{$\underset{\text { (ml./min.) }}{\mathbf{u}}$} & \multicolumn{2}{|c|}{$\begin{array}{l}\text { Dividing } \\
\text { Values }\end{array}$} & \multicolumn{4}{|c|}{ 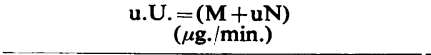 } & \multicolumn{3}{|c|}{$\underset{(\mathrm{mg} . / 1 .)}{\mathbf{F}}$} & \multicolumn{2}{|c|}{$\underset{(\mathrm{ml} . / \mathrm{min} .)}{\mathrm{f}}$} \\
\hline & & & $\stackrel{\text { u. }}{(\mathrm{ml} / \mathrm{min} .)}$ & $\underset{\text { (mg./1.) }}{\mathrm{U}}$ & $\mathbf{M}$ & $\sigma \mathbf{M}$ & $\mathbf{N}$ & $\sigma \mathrm{y} . \mathrm{x}$ & $\mathbf{n}$ & Range & Mean & & $\sigma \mathrm{f}$ \\
\hline $\begin{array}{l}3 \\
4 \text { iv } \\
\text { vi }\end{array}$ & $\begin{array}{l}30 \\
16 \\
16 \\
12 \\
23 \\
21 \\
24 \\
24 \\
40 \\
40\end{array}$ & $\begin{array}{l}0.70-11.45 \\
0.38-0.74 \\
0.43-4.62 \\
0.28-0.62 \\
0.71-13.00 \\
0.41-0.82 \\
1.03-5.24 \\
0.30-0.85 \\
0.85-6.70 \\
0.33-1.02\end{array}$ & $\begin{array}{l}0.75 \\
0.50 \\
0.81 \\
0.99 \\
1.07\end{array}$ & $\begin{array}{l}2,000 \\
2,500 \\
1,500 \\
1,000 \\
1,000\end{array}$ & $\begin{array}{l}1,428(1,450) \\
1,150 \\
1,158(1,185) \\
1,224 \\
1,080(1,142) \\
901 \\
952(1,000) \\
706 \\
862 \quad(903) \\
726\end{array}$ & $\begin{array}{r}70 \\
117 \\
68 \\
78 \\
55 \\
104 \\
83 \\
45 \\
46 \\
74\end{array}$ & $\begin{array}{c}15^{*} \\
519 \\
28^{*} \\
180 \\
48^{*} \\
475^{*} \\
25^{*} \\
293 \\
26^{*} \\
374^{*}\end{array}$ & $\begin{array}{r}169 \\
162 \\
173 \\
114 \\
107 \\
156 \\
93 \\
124 \\
90 \\
235\end{array}$ & $\left\{\begin{array}{l}3 \\
1 \\
3 \\
3 \\
3 \\
4 \\
4\end{array}\right.$ & $\begin{array}{l}10 \cdot 5-12 \cdot 6 \\
10 \cdot 8-11 \cdot 7 \\
12 \cdot 8-14 \cdot 0 \\
11 \cdot 1-11 \cdot 8 \\
11 \cdot 3-12 \cdot 6\end{array}$ & $\begin{array}{l}12 \cdot 0 \\
10 \cdot 3 \\
11 \cdot 6 \\
11 \cdot 2 \\
13 \cdot 5 \\
11 \cdot 5 \\
12 \cdot 0\end{array}$ & $\left\{\begin{array}{l}121 \\
43 u+96 \\
115 \\
17 u+119 \\
98 \\
41 u+78 \\
89 \\
22 u+52 \\
79 \\
20 u+66\end{array}\right.$ & $\begin{array}{r}6 \\
10 \\
7 \\
8 \\
5 \\
9 \\
7 \\
3 \\
4 \\
6\end{array}$ \\
\hline
\end{tabular}

* These values of $\mathbf{N}$ are not significant. The values of $\mathbf{M}$ in parenthesis are those if $\mathbf{n}$ is taken as 0 . The overlap in ranges of $u$ at high and low flows is due to the division being made at a value of $U$, not $u$. 
TABLE II

CREATININE CLEARANCES AND EXPECTED INULIN

\begin{tabular}{|c|c|c|c|c|c|}
\hline \multirow{3}{*}{$\begin{array}{l}\text { Subject } \\
\text { and Sex }\end{array}$} & \multirow{3}{*}{$\begin{array}{c}\text { Age } \\
\text { (Years) }\end{array}$} & \multirow{3}{*}{$\begin{array}{c}\text { Surface } \\
\text { Area } \\
\text { (sq.m.) }\end{array}$} & \multicolumn{3}{|c|}{ Clearances } \\
\hline & & & \multicolumn{2}{|c|}{ Creatinine } & \multirow{2}{*}{$\begin{array}{c}\text { Inulin* } \\
\text { (ml./min. } \\
\text { per } \\
1.73 \text { sq.m. }\end{array}$} \\
\hline & & & $\underset{\text { (ml./min.) }}{\text { Actual }}$ & $\begin{array}{l}\text { ml.min. } \\
\text { per } \\
1.73 \text { sq.m. }\end{array}$ & \\
\hline $\begin{array}{l}\text { 1. Male. } \\
\text { 2. } \quad " \quad \cdots \\
\text { 3. } ", \quad . \\
\text { 4. Female }\end{array}$ & $\begin{array}{l}32 \\
39 \\
29 \\
50\end{array}$ & $\begin{array}{l}2.17 \\
1.96 \\
1.81 \\
1.92\end{array}$ & $\begin{array}{r}121 \\
115 \\
98 \\
89\end{array}$ & $\begin{array}{r}97 \\
102 \\
93 \\
80\end{array}$ & $\left\{\begin{array}{l}127 \\
118\end{array}\right.$ \\
\hline
\end{tabular}

* Smith, 1951.

\section{Discussion}

These results show that in normal subjects the excretion of creatinine remains very constant at urine flows above about 0.5 to $1.0 \mathrm{ml} / / \mathrm{min}$., the coefficient of variation being $5-9 \%$ in different subjects, but that at lower flows the excretion rate falls. Similarly the creatinine clearance is constant at high flows, but falls at lower ones. This is in agreement with the findings of Chesley (1938), but in his subjects the fall did not take place till the urine volume fell below about $0.35 \mathrm{ml} . / \mathrm{min}$.

Qualitatively there is thus a good agreement between the clearance of creatinine and inulin, which is the most generally accepted measure of filtration rate. Many workers have found constant inulin clearances at higher flows, and Chasis and Smith (1938) found a slight decrease at low flows.

Quantitatively the agreement is not so good, the creatinine clearance being lower than the expected filtration rate measured by inulin clearance. This could be due to tubular reabsorption of creatinine, but only if a constant amount is reabsorbed whatever the urine flow. Although there is evidence that exogenous creatinine is secreted by the tubules, and it has been suggested that this may also occur with the endogenous form (Brod and Sirota, 1948), reabsorption has not been suggested, and the most probable cause of the discrepancy is that the creatinine clearances are lower than the inulin clearances because the values obtained for serum creatinine are too high. This was discussed in a previous paper (Roscoe, 1953), where it was shown that if, as has been found, $20 \%$ of the estimated chromogen is not creatinine, the difference in the clearances would be accounted for.

If this is so, although the creatinine clearances do not accurately measure the filtration rate, they do provide accurate measurements of any changes in rate which may occur, and so are valuable tools in the investigation of kidney function, especially in long-term experiments where inulin clearances cannot be used.

\section{Summary}

In four normal subjects the excretion rates of endogenous creatinine were unaffected by changes in urine volume, except when this fell to low volumes. This suggests that creatinine is not handled by the kidney tubules and that changes in its rate of excretion can be used as a measure of changes in filtration rate.

The creatinine clearance was in each case lower than the expected filtration rate, but this is considered to be due to over-estimation of the plasma creatinine.

\section{REFERENCES}

Brod, J., and Sirota, J. H. (1948). J. clin. Invest., 27, 645.

Chasis, H., and Smith, H. W. (1938). Ibid., 17, 347.

Chesley, L. C. (1938). Ibid., 17, 591 .

Roscoe, M. H. (1953). Journal of Clinical Pathology, 6, 201.

Smith, H. W. (1951). The Kidney. Oxford University Press, New 